\title{
El TDHA A TRAVÉS DE LOS OJOS DE UNA MAESTRA
}

\author{
Marisol Camargo Zamata
}

\begin{abstract}
RESUMEN
EI TDHA es un trastorno que afecta a casi el doce por ciento de los estudiantes. Sus características son predominantemente impulsivas, desconcentración, inquietud y movimiento del cuerpo constante. Para manejarlo se necesita del concurso de varios profesionales, entre los cuales están los médicos, psicólogos y maestros. Los docentes debemos estar bien informados para que en el aula podamos controlar mejor las situaciones de los niños y conducirlos de una manera profesional y con ingentes recursos pedagógicos que servirán de apoyo para el manejo acertado de esta problemática.
\end{abstract}

\section{PALABRAS CLAVE}

Química cerebral, terapia, medicación, seguimiento, autoestima.

\section{ABSTRACT}

The ADHD is a disorder which affects nearly twelve percent of students. The characteristics are predominantly impulsive, deconcentration, restlessness and constant body movement. The assistance of several professionals is required to handle, including doctors, psychologists and teachers. Teachers should be well informed so that in the classroom we can better control the situations of children and lead them in a professional way and with enormous teaching resources that will support the successful management of this problem.

\section{KEYWORDS}

Brain chemistry, therapy, medication, monitoring, self-esteem.
$\mathrm{P}$ ero has notado que Paula está más movida? ¿Y qué me dices de Saúl? No puede estar quieto un solo momento iPara en la luna! ¿Y qué me dices de Sara? No deja de moverse en su sitio y no para de hablar. Estos chicos son muy engreídos, les voy a mandar una sanción, llamaré a sus padres y su conducta va a ser muy baja este bimestre.

\section{- iEstos niños me estresan!}

Cuántas veces los maestros no habremos hablado así en alusión a nuestros estudiantes. Algunos, tal vez, con delicadeza les decían que se pongan a trabajar, sino obtendrían una mala nota; otras más inexpertas, les dirían, en medio de la clase a los niños en cuestión, "iTe voy a sacar fuera del salón como sigas con ese comportamiento! iNo paras de hablar, llamaré a tus padres!" Y así, hay una retahíla de expresiones amenazantes que buscaban la paz del salón y el trabajo silencioso. Dos aspectos que deben anularse en la pedagogía que se practica hoy. Generalmente este tipo de actitudes de los alumnos son manifestadas al departamento de Psicología, trasmitidos a la tutora y un poco menos, a la dirección del colegio.

Algunos de los mencionados, se quedan mirando el patio, esperando que el recreo venga pronto; otros, tratan de copiar lo que está en la pizarra, pero lo hacen a disgusto y con pobre caligrafía; hay una niña que interrumpe la clase cada cierto tiempo. También están los que no paran de hablar todo el tiempo, los que no terminan las actividades y sus cuadernos no están ni limpios ni organizados.

¿Son niños malcriados? ¿Son engreídos y flojos? ¿No te has puesto a pensar que esas actitudes y acciones podrían 
tratarse de un problema del que los maestros no están informados como debiera ser? También he escuchado decir: "Hoy no tomó su pastillita, por eso está así" o "está más inquieto, deben subirle la dosis del Ritalín, Concerta u otros..." Sus compañeros los tildan de mongo, loquito, etc. El bullying ya está presente para hacerles aún más difícil la vida de estos niños con TRASTORNO DE ATENCIÓN E HIPERACTIVIDAD (TDAH).

\section{Pero, ¿qué es el TDAH?}

Según Armando Filomeno, catedrático y especialista en este tema, este trastorno es neuropsiquiátrico debido a un desequilibrio bioquímico cerebral caracterizado por la falta de atención, de hiperactividad, impulsividad o de una combinación de todos ellos.

Son cada vez más las familias y niños y jóvenes que los sufren y muchos de ellos no han tomado las decisiones correctas para controlar estas características y sufren cada día pesadillas que interfieren en todos los ámbitos en los que se desenvuelven los niños o jóvenes. Algunos padres se desentienden del problema, las madres pueden ser más permisivas y preocupadas, por lo que se cree, es el desborde de una mala conducta.

En este artículo no me voy a referir a los desequilibrios químicos ni profundizar temas sobre medicación. Me ocuparé, desde mi experiencia propia, en comentar y explicar algunas medidas que se pueden tomar para que el estudiante con una autoestima en formación, pase del fracaso al éxito, de perdedor a ganador, de manera que todo ello resulte en una armónica vida saludable en la escuela, universidad, trabajo y familia. Sea infante, niño o adolescente se sobreponga a su situación y empiece a rendir positivamente y de manera progresiva, tanto en lo académico como en lo conductual.

El niño en clase y en casa, debe tener organizado su día. Si chequeamos que las tareas están bien escritas en su agenda, le damos las reglas cortas, claras y mirándolo a los ojos, hay mejor pronóstico de controlar y monitorear el avance del estudiante; si vemos que él no avanza al mismo ritmo de los demás, apliquemos la evaluación diferenciada en la que la exigencia sea menor y le tome menos tiempo. Hay que recordar que todos los niños tienen particularidades únicas $y$, a veces en las evaluaciones, no podemos medirlos a todos porigual.

Un maestro como norma general, debe contar con una gran cantidad de material de apoyo para que los niños con este trastorno se vean ocupados en una batería de actividades lúdicas y que les exija mantener su atención y controlar su impulsividad.

Haré un paréntesis para indicar que una persona diagnosticada con este trastorno, necesita de la intervención de varias personas como un neuropediatra, a veces un psiquiatra (algunos caen en depresión) y de forma aún más estrecha, maestros y tutores.

Los maestros debemos elaborar nuestras clases de forma colaborativa siempre, así el niño o joven se sentirá como parte importante pues no está negado para participar. También es prioritario que no se le etiquete como el nerviosito, el que no puede, el malcriado; al contrario, desde su interior, ellos claman por ayuda y por ser aceptados dentro de los grupos de su entorno, como todo el mundo. Ser aceptados es algo muy marcado en ellos, sobre todo en la adolescencia en que están construyendo su identidad y perfilando su valoración personal. Son estudiantes con características difíciles, pero que con una adecuada intervención, llevadera en el tiempo.

Es importante mencionar que un niño diagnosticado con este trastorno, no ha sido debido a unos padres que no supieron criarlo o no fueron lo suficientemente firmes para erradicar conductas consideradas inadecuadas. Es más, este no es un problema de conducta, no es portarse mal pues no está en el niño o joven poder manejarlo por él mismo, aún si ha habido un conjunto de personas prestas a ayudarlo.

Tampoco significa que el niño no sea inteligente; al contrario, puede ser muy inteligente y una maestra diestra, sabrá manejar la problemática de manera profesional y con recursos de actividades animadoras, grupales, en las que a ese niño o joven, se le encomiende labores según sus 
capacidades. Las maestras deben reforzar positivamente cada logro, cada trabajo concluido, cada intervención acertada, por muy pequeñas que estas sean. Pero también es cierto que el niño debe ser insertado en un colegio a la altura de sus aptitudes. Algunas veces, cuando el cuadro es severo, se deberá buscar centros de enseñanza con pocos alumnos y en otros casos, y si la economía lo permite, buscar un tutor para que lo apoye por las tardes.

Se recomienda que todos los miembros de una entidad educativa deben estar informados y clarificados en lo que es un TDHA, pues con el conjunto de todos, podremos allanar el camino de los estudiantes, aliviar a los padres y llevar a los chicos a una vida académica y social más congruente con sus características. Invitar a un profesional en este campo para que informe, recomiende y explique a los maestros es una tarea insoslayable.

Finalmente, quiero remarcar que ser maestro es una vocación de servicio, para aquellos que saben de su influencia positiva en los educandos, que los maestros también somos modelos y fuente de inspiración y que no hay tarea más gratificante que observar lo logros de los pupilos. Es también un reto para demostrar que, como docentes, estamos aptos para atender cualquier característica o necesidad que se presente en nuestra aula y enfrentarlo con estrategias variadas. La pedagogía de este siglo ya no es aquella en la que cumplir un programa era lo prioritario, el llenar de contenidos a los niños con tareas excesivas y poco significativas no corresponden a la modernidad.

Es importante destacar que los maestros siempre tenemos reuniones a nivel general en la cual un invitado, conocedor del tema, podría explicarnos mejor las características del tema y así tener todos la información de primera mano. Un adecuado y consistente diálogo con el departamento de psicología, con los padres, terapeutas, neurocirujanos y con los demás profesores, es una muy buena estrategia para que todos los involucrados tomemos cartas en el asunto y sepamos organizarnos, de tal forma, que el estudiante desarrolle sus habilidades y capacidades. No hay mejor recompensa para un MAESTRO.

\section{REFERENCIAS}

Filomeno, A. (2015). El niño con déficit de atención o hiperactividad. Lima, Perú: Centro Editorial UPCH.

Vásquez, Josué; Cárdenas, Eva Marcela; Feria, Miriam; Benjet, Corina; Palacios, Lino; De la Peña, Francisco (2010). Guía Clínica para el tratorno por Déficit de Atención e Hiperactividad. México: Soshana Berenzon.

http://www.tdahytu.es/blog/ Recuperado el 21$10-16$. 